\title{
Hepatocellular Carcinoma in Albania: Incidence and Risk Factors
}

\author{
Bashkim Resuli ${ }^{1}$, Agim Sallaku ${ }^{2}$ \\ ${ }^{1}$ University Service of Gastrohepatology, Faculty of Medicine, Tirana, Albania \\ ${ }^{2}$ University Service of Oncology, Faculty of Medicine, Tirana,Albania
}

\begin{abstract}
Background: Hepatocellularcarcinoma represent a challenging malignancy of worldwide importance. Aim: To assess the incidence and the potential impact of the risk factors. Methods: It was a hospital-based case-control study of 648 HCC patients between January 2000 and November 2014. The age-adjusted incidence rates were calculated for 5-years period. Liver cirrhosis was designed by biopsy or in the presence of unequivocal clinico-biochemical and ultrasonographic data. HCC was defined in cirrhotic subjects by CT or MRI. For subjects without cirrhosis cytological confirmation was mandatory. Results: Studypopulation comprised 527 ( $77.1 \%$ ) males and 157 (22.9\%) female, given M:F ratio of 3.4:1. The mean age of all patients was 60.4 years, with majority of them ( $70 \%$ ) between 50 and 70 years. Underlying cirrhosis was present in $89.3 \%$ of cases, and $68 \%$ of them were Child-Pugh class A. The overall ageadjusted incidence rates started to increase in 2010, from 6.6 and 7.4 per 100000 population in 2000 and 2005 respectively, to 8.9 in 2010 and 9.3 in 2014, nearly 4 times higher in man than in women. The greater incidence occurred in patients 60 and 70 years of age. $50.9 \%$ of all cases were associated with $\mathrm{HBV}$ infection, $21.8 \%$ with concomitant $\mathrm{HBV}$ infection and alcoholism, $13.8 \%$ with alcoholic alone, $8 \%$ with $\mathrm{HCV}$ infection, and $4.9 \%$ were $\mathrm{HCC}$ patients with not a reliable risk factor. Conclusions: The incidence rates of HCC has almost doubled in Albania between 2000 and 2014. HBV infection and heavy alcohol consumption significantly influenced for the increased incidence of HCC in our country.
\end{abstract}

Keywords: Hepatocellular carcinoma, HBV infection, HCV infection, alcoholism, incidence

\section{Introduction}

Hepatocellular carcinoma (HCCC) is the fifth most common neoplasm worldwide (1), with over a million new cases diagnosed annually $(2,3)$. Its incidence differs considerably in different geographical regions, with more than $80 \%$ of cases occurring in resource-poor countries $(3,4)$. Several epidemiological studies have documented a dramatic increase in the incidence of HCC; it doubled during the last 20 years and is expected to peak between 2015 and 2020 (5). In addition, the incidence of the tumor is increasing in a number of countries in which it previously had low or an intermediate occurrence rate $(6,7)$. The number of death per year, attributed to the liver cancer is almost identical to its incidence (1), making it the second cause of cancer related mortality in the world, and the ninth leading cause of cancer death in United States (8).

HCC is unusual among human cancers because of the causative agent is often clear. However, there are multiple etiologic factors affecting HCC, making HCC an extremely complex condition associated with poor prognosis (9). The commonest and geographically most widely distribution of the recognized causes of HCC are chronic HBV and HCV infection, and cirrhosis whatever its cause (10). The relative risk of $\mathrm{HCC}$ in patients with chronic hepatitis $\mathrm{B}$ or chronic hepatitis $\mathrm{C}$ infection is about 25-30 times higher that of those without the infection (11). Changes in the time trends of HCC and variations in its age, sex and race-specific rates among different regions are likely to be related to differences in hepatitis viruses that are most prevalent in a population, the timing of their spread, and the ages of the individuals the viruses infect (12).

$\mathrm{HCC}$ is one of the major consequencesof chronic hepatitis B, and variety of viral load and host factors contribute to its development.It is now well documented that $70-90 \%$ individuals who develop HCC in the setting of $\mathrm{HBV}$ infection have cirrhosis (13). In hepatitis $\mathrm{B}$ virus-related cirrhosis, the 5-yearcumulative risk for $\mathrm{HCC}$ is $15 \%$ in high endemic areasand 10\% in the West (6).

Chronic HCV infection is another important global cause of HCC, especially in developed countries. Significant increase in the incidence of HCC that have been observed over the past two decades in the United States has been mainly attributed to the large reservoir of long-standing chronic hepatitis $\mathrm{C}(5,14)$. The rate of $\mathrm{HCC}$ among $\mathrm{HCV}$ infected persons ranges from $1 \%$ to $3 \%$ over 30 years (12).

Heavy alcohol intake has been definitely recognized as a cause of chronic liver disease, including HCC (15). In the USA and Austrian cohorts, alcoholic liver disease appears to account for $24-35 \%$ of cases of HCC (16). The annual incidence of $\mathrm{HCC}$ was reported at around $2.5 \%$ among Child-Pugh class A or B alcoholic cirrhosis (15). In the absence of HBV and HCV infections, and alcohol abuse, dietary aflatoxin exposure (17), non-alcoholic steatohepatitis (18), and iron overload (19) have been robustly associated with the risk of developing HCC.

The aim of the present study was to investigate the incidence rates and the potential impact of the risk factors of HCC in Albania.

\section{Methods}

We conducted a hospital-based case-control study in which a total of $648 \mathrm{HCC}$ patients routinely attending the liver unit and oncologic service of the University Hospital Center " Mother Theresa" in Tirana between January 2000 and November 2014.We defined as incident cases all new cases of HCC diagnosed during the enrolment period. The ageadjusted incidence rates for $\mathrm{HCC}$ were calculated for 5-years 


\section{International Journal of Science and Research (IJSR) \\ ISSN (Online): 2319-7064}

Index Copernicus Value (2013): 6.14 | Impact Factor (2014): 5.611

period between 2000 and 2014. The data concerning each case were collected only once, at the first contact with the patients during the study period.

Liver cirrhosis was diagnosed by liver biopsy or in the presence of unequivocal clinical, biochemical and ultrasound signs (20). The Child-Pugh criteria were used for the grading of cirrhosis. Heavy alcohol consumption was defined as consumption of $>80 \mathrm{~mL}$ of ethanol per day for the least 10 years before development of the liver disease.HCC was defined in cirrhotic subjects by one imaging technique (CT scan and MRI) showing a nodule larger than $2 \mathrm{~cm}$ with contrast uptake in the arterial phase and contrast washout in venous or late phases or two techniques showing this radiological behavior for nodules 1$2 \mathrm{~cm}$ in diameter. Cytohistological confirmation was required for subjects who do not fulfilled this accepted criteria (21). For subjects without cirrhosis histological confirmation was mandatory. Tumor characteristics included staging (based on Barcelona Center for Liver Cancer classification ) and vascular involvement (22).

Serum hepatitis B surface antigen ( $\mathrm{HBsAg}$ ), $\mathrm{HBeAg}$ and anti-HDV were tested using a radioimmunoassay kit ( Abott Laboratories ). Anti-HCV was measured by means of second generation enzyme immunoassay ( Abott Laboratories ). Serum biochemical tests were performed by a systemic multiautoanalyser( Technicon SMAC ). Serum alphafetoprotein ( AFP ) level was measured by ELISA, and an AFP value greater than $20 \mathrm{ng} / \mathrm{ml}$ was considered abnormal

The study protocol was approved by the ethical committee.

The mean and standard deviation was used to present continuous variables. The discrete variables were presented in absolute number and percentage. T-test and Hi-square test was used to see the differences between two groups ( for continuous variables ). A P-value $<5 \%$ was considered statistically significant.

\section{Results}

Between 2000 and 2014 there were 648 cases of HCCs. The mean age of all patients was 60.4 years, with majority of them $(70 \%)$ between 50 and 70 years. HCC was rare among individuals younger than 40 years of age. Study population comprised $527(77,1 \%)$ males and 157 (22.9\%) female, given $\mathrm{M}: \mathrm{F}$ ratio of 3,4:1. Underlying cirrhosis was present in $89.3 \%$ of cases, and $68 \%$ of these cases were Child-Pugh class A.

Among 648 cases tested for hepatitis virus markers, $74.1 \%$ were $\mathrm{HBsAg}$ positive, $8.1 \%$ anti-HCV positive and many as $18,2 \%$ were negative for both viral markers. Thirty five percent of the subjects were heavy drinkers, $21.5 \%$ of them were alcoholic cirrhotic patients with concomitant HBV infection.

The age-adjusted incidence rates of liver cancer among Albanian man and women for consecutive 5 years period between 2000 and 2014 is shown in Fig 1a. The overall ageadjusted incidence rates of HCC started to increase in 2010 , from 6,6 and 7.4 per 100 000population in 2000 and 2005, respectively, to 8.9 in 2010 and 9.3 in 2014 . The ageadjusted incidence rates of HCC were nearly 4 times higher in man than women.

The age distribution of new cases with HCC for consecutive 5-years period from 2000 and 2014 is shown in Fig 1b. The incidence has increased in most age group older than 50 years, with the exception of age group 70 to 80 years. The greatest incidence occurred in patients 60 and 70 years of age. Concomitant with the increase in incidence, the age distribution of patients with HCC progressively shifted towards younger persons ( $32 \%$ of the patients with HCC were included in age-group of 50 and 60 years ).
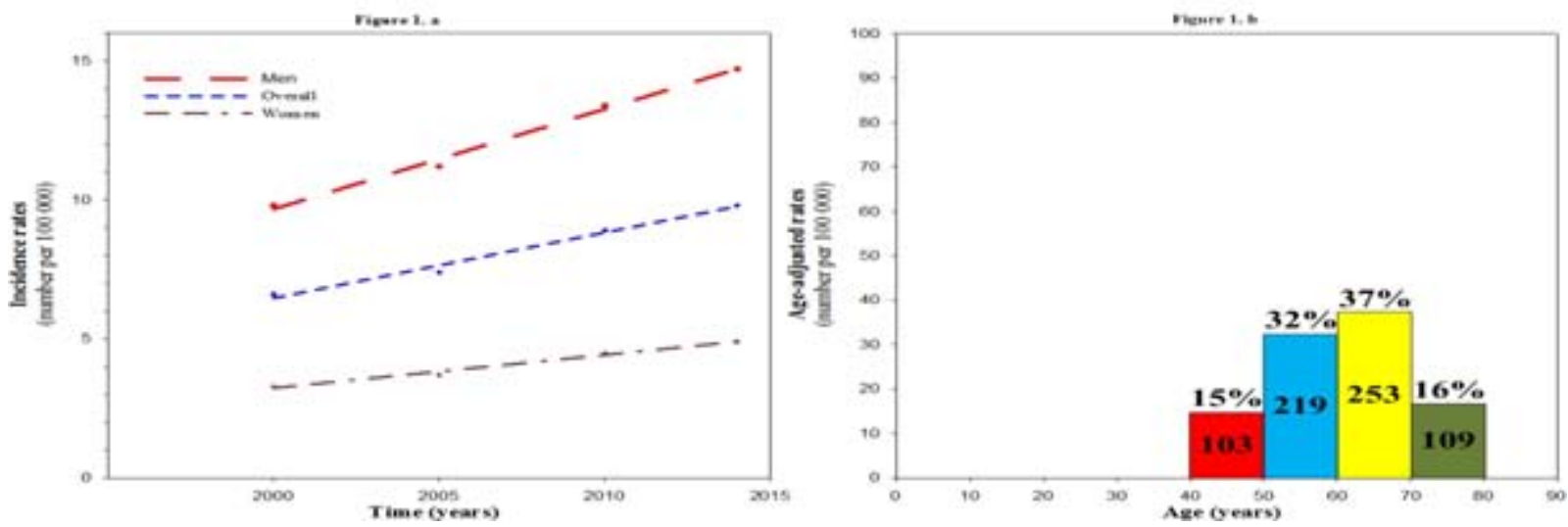

Figure 1: a. Trends in HCC incidence rates over time in Albania (expressed as the number per 100000 population) b. Age adjusted incidence rates of HCC in 2014 in Albania (expressed as the number per 100000 population)

The proportion of HCC cases positive for the main risk factors are shown in Tab 1. Half of all cases of HCC were associated with hepatitis B virus infection, with a further $21,5 \%$ associated with heavy alcohol consumption and only $0.9 \%$ with diabetes mellitus. Other risk factors for developing HCC include alcoholic cirrhosis ( $13.8 \%$ of the cases ) and hepatitis $\mathrm{C}$ virus infection, in $8 \%$ of all subjects with HCC enrolled in this study, differently to other countries. In $4.9 \%$ of the patients with HCC there were not a reliable risk factor. 


\section{International Journal of Science and Research (IJSR) \\ ISSN (Online): 2319-7064}

Index Copernicus Value (2013): 6.14 | Impact Factor (2014): 5.611

Table 1: Risk Factors of HCC

\begin{tabular}{|c|c|c|}
\hline Risk Factors & No. & \% \\
\hline HBV & 348 & 50.9 \\
\hline HBV+ALCOHOL & 147 & 21.5 \\
\hline ALCOHOL & 94 & 13.8 \\
\hline HCV & 55 & 8 \\
\hline DIABETUS+HBV & 6 & 0.9 \\
\hline CRYPTOGENIC & 34 & 4.9 \\
\hline
\end{tabular}

The baseline characteristics of cirrhotic patients with concomitant HBV infection and alcoholism, HBV infection alone and alcoholism alone are shown in Tab 2. The rate was $21.4 \%, 50.9 \%$ and $13.8 \%$ in cirrhotic patients with concomitant HBV infection and alcoholism, HBV infection alone and alcoholism alone, respectively.

Table 2: Demographic data of cirrhotic patients with concomitant HBV infection and alcohol, HBV infection alone and alcoholism alone

\begin{tabular}{|c|c|c|c|}
\hline Characteristics & HBV + Alcohol $(n=130)$ & HBV $(n=310)$ & Alcohol $(n=84)$ \\
\hline Age $(\mathrm{y})[$ Mean $\pm(\mathrm{SD})]$ & $42.8 \pm 9.7(\mathrm{a}, \mathrm{b})$ & $46.7 \pm 8.9$ & $47.2 \pm 10.1$ \\
\hline AST $[$ Mean $\pm(\mathrm{SD})]$ & $95 \pm 32.6(\mathrm{a}, \mathrm{b})$ & $60 \pm 34(\mathrm{c})$ & $120 \pm 80$ \\
\hline ALT $[$ Mean $\pm(S D)]$ & $60 \pm 48(a, b)$ & $80 \pm 40(c)$ & $45 \pm 28$ \\
\hline Bilirubin $[$ Mean $\pm(\mathrm{SD})]$ & $2.2 \pm 0.8(\mathrm{a})$ & $1.4 \pm 0.6(\mathrm{c})$ & $2.4 \pm 0.8$ \\
\hline Alkaline phosphatase [Mean $\pm(\mathrm{SD})]$ & $280 \pm 120$ (a) & $210 \pm 135(\mathrm{c})$ & $260 \pm 120$ \\
\hline Platelet count $[$ Mean $\pm(\mathrm{SD})]$ & $80 \pm 24 \mathrm{a},(\mathrm{b})$ & $135 \pm 45(\mathrm{c})$ & $125 \pm 45$ \\
\hline Albumin $[$ Mean $\pm(\mathrm{SD})]$ & $3,4 \pm 0.6$ (a) & $3.6 \pm 0.7(\mathrm{c})$ & $3.4 \pm 0.4$ \\
\hline A-feto $<20 \mathrm{mg} / \mathrm{ml}(\%)$ & $76(58 \%)$ & $155(50 \%)$ & $44(54 \%)$ \\
\hline A-feto $21 \div 200 \mathrm{mg} / \mathrm{ml}(\%)$ & $42(32 \%)$ & $103(33 \%)$ & $31(36 \%)$ \\
\hline A-feto> $200 \mathrm{mg} / \mathrm{ml}(\%)$ & $14(10 \%)$ & $52(17 \%)$ & $25(18 \%)$ \\
\hline Child-Pugh A (\%) & $73(56 \%)(a, b)$ & $227(73 \%)$ & $58(69 \%)$ \\
\hline Child-Pugh B (\%) & $31(24 \%)$ & $52(17 \%)$ & $16(19 \%)$ \\
\hline Child-Pugh C (\%) & $26(20 \%)(a, b)$ & $31(10 \%)$ & $10(12 \%)$ \\
\hline
\end{tabular}

- Data shown as median (range) or number $(\%)$;

- ${ }^{\text {ap }}$ value $<0.05 \mathrm{HBV}+$ ALCOHOL vs HBV

- ${ }^{b} p$ value $<0.05 \mathrm{HBV}+$ ALCOHOL vs ALCOHOL

${ }^{c} \mathrm{p}$ value $<0.05 \quad \mathrm{HBV}$ vs ALCOHOL

The mean age of patients with concomitant HBV infection and alcoholism was significantly higher than that in subjects with HBV infection alone or alcoholism alone, $42.8 \pm 9.7$ vs $46.7 \pm 8.9$ vs $47.2 \pm 10.1, \mathrm{p}=0.013$ and $\mathrm{p}<0.001$, respectively. The mean of AST level of patients with alcoholic cirrhosis was much higher than that in patients with HBV infection and those with concomitant $\mathrm{HBV}$ infection and $\mathrm{HBV}$ infection alone, $120 \pm 80$ vs $60 \pm 34$ vs $95 \pm 32$, $p<0.001$, while the mean of ALT level of subjects with HBV infection alone was significantly higher than that in subjects with alcoholism, $80 \pm 40$ vs $45 \pm 28, \mathrm{p}<0.001$. Concerning the Child-Pugh class, the rate of A class of patients with concomitant HBV infection and alcoholism was significantly less than the rate in patients with $\mathrm{HBV}$ infection and alcoholism and alone, $56 \%$ vs $73 \%$ vs $69 \%$, p< 0.001 .

\section{Discussion}

The most important finding of this study is the evident increase of the incidence rates of HCC from 2000 to 2014. There is no doubt that this conspicuous rising incidence is related to the high prevalence of $\mathrm{HBV}$ infection in our country. It is now well documented that HCC is one of the major consequences of chronic hepatitis $\mathrm{B}$ and that individuals who develop $\mathrm{HCC}$ in the setting of HBV infection have cirrhosis.Meta-analysis of case-control and cross-sectional studies indicated that the lifetime relative risk for HCC was 15-20 time higher among HBsAg-positive individuals, compared with HBsAg-negative individuals and that the incidence rates of $\mathrm{HCC}$ in subjects with chronic HBV infection in East Asian countries to be 0.2 per 100000 persons-years in inactive carriers, 0.6 person-years for those with chronic HBV infection without cirrhosis, and 3.7 person-years for those with compensated cirrhosis (23). Factors that have been reported to increase HCC risk among HBV carriers are demographic (male sex, older age, ancestry, family history for HCC), viral (higher levels of HBV replication, HBV genotype, longer duration of infection, co-infection with HCV, HIV or HDV virus), clinical (cirrhosis) and environmental (heavy intake of alcohol, exposure to aflatoxin or tobacco) (12).

Hepatitis B is a disease of global distribution. It is estimated that approximately $45 \%$ of the world's population live in region endemic for HBV infection, about $30 \%$ of the world's population, i.e. nearly 2 billion people show serological evidence of hepatitis B virus (HBV) infection and about 40 million are persistent carriers of HBV ( 24). Each year over one million people die from HBV-related chronic liver disease, including cirrhosis and HCC (25). The endemicity of HBV infection varies greatly worldwide and is influenced primary by the age at which infection occurs (26). In fact, almost all infection occur either during the prenatal or early in a childhood, which occurs for the high rates of chronic HBV infection in these populations (27).

Epidemiologic situation of HBV infection in Albania before 1995 has been described as very grave and dangerous, with prevalence rates of $\mathrm{HBsAg}$ and Anti-HCV similar to those in hyperendemic countries, $18 \%$ and $62 \%$ respectively (28, 29). This epidemiologic situation explain very well the fact that half of all our cases of HCC are associated with hepatitis B virus infection, with a further $21.5 \%$ and $0.9 \%$ associated with alcoholism and diabetes, respectively. Since May 1995, Albania introduced vaccination of new born children against $\mathrm{HBV}$ into the National Immunization 


\section{International Journal of Science and Research (IJSR) \\ ISSN (Online): 2319-7064 \\ Index Copernicus Value (2013): 6.14 | Impact Factor (2014): 5.611}

Program as the most appropriate immunization strategy to reduce the rates of $\mathrm{HBV}$ infection and $\mathrm{HBV}$-related chronic liver disease, including HCC. In 2007, despite the estimated two-fold reduction of HBsAg prevalence (9.5\%), Albania remains a highly endemic country (30). Development of $\mathrm{HBV}$ vaccine has been a major success in reducing of $\mathrm{HBV}$ infection and subsequent development of HCC. In 1884, Taiwan become the first country to vaccinate newborns against $\mathrm{HBV}$ infection, and give $\mathrm{HB}$ immunoglobulin to infants of high risk (HBsAg-positive and $\mathrm{HBeAg}$-positive) mothers. Since then, HBV carriers rate among children has been decreased to $1.2 \%$ and incidence of HCC among vaccinated children decreased by $70 \%$ (31). However, the $\mathrm{HBV}$-related incidence of $\mathrm{HCC}$ is procepted to increase for several decades because of the high prevalence of chronic HBV infection and prolonged latency to HCCdevelopment (32).In parallel with the very high prevalence of $\mathrm{HBV}$ infection, the rising incidence of HCC in our country could be also elucidated through improvement in screening programs and diagnosis tools, as well as the increased survival role among patients with cirrhosis allowing time for some of them to develop HCC.

There are striking differences in the incidence of HCC related to age and gender. Variations in different geographic regions are likely to be related to the differences in the prevalence of hepatitis viruses in the population, as well as the timing of the spread of the viral infection and the age of the individuals at the time of the infection. In Albania, the presence of one or more serological markers of HBV infection and the high rate of infection in children 1 to 10 years, confirms that the HBV infection was largely acquired by mother-child transmission or in early childhood. Indeed, our data shown a shift towards younger age case than in low-endemic areas. The high male : female ratio of HCC in our study might be related to the fact that man are at increasing risk for HCC partly because they have a greater incidence of viral hepatitis and alcoholic cirrhosis. On the other hand, high serum level of testosterone have been associated with HCC risk in nested case-control studies of HBV carriers (33).

Alcohol intake has been definitely recognized as a cause of chronic liver disease, including HCC. Albania is actually a country where use of alcohol beverages with ethanol content (rakee) is very diffuse habit. Heavy and very heavy drinkers (15-20\% of population), are really at high risk for advanced liver disease (34). This study clearly showed that heavy alcohol intake (daily consumption of more than $80 \mathrm{~mL}$ of ethanol) is an important independent risk factors for HCC (13.8\% alcoholic alone and $21.5 \%$ concomitant of alcoholism with HBV infection ). In US and Austria, cohorts study confirmed that alcoholic liver disease appears to account for $24-35 \%$ of cases of $\operatorname{HCC}(35,36)$. Recent data showed that the risk of HCC is increased in the alcoholicrelated disease (OR 4.06) and represent the second greatest population-attributable fraction (PAF) of risk factors for HCC (16). The annual incidence of HCC was reported at around $2.5 \%$ among Child-Pugh class A or B alcoholic cirrhosis in Spain, with higher annual incidence in those 55 years of age and older and platelet count less than 125000 $\mathrm{mm}^{3}$ (15). On the other hand, this study showed once more the role of association between heavy alcohol consumption and chronic hepatitis B virus infection in the etiology of HCC (21,5\% of the cases). In this occasion, a Japanese study of patients with compensated HBV-liver cirrhosis, showed that heavy alcohol consumption increase the risk for HCC 3 fold (37). Furthemore, a population-based cohort study found that among individuals with chronic HBV infection, the risk for HCC increased significantly among subjects with an alcohol intake of $50 \mathrm{~g} / \mathrm{g}$, with a relative risk of 1.2 for 50 $99 \mathrm{~g} / \mathrm{d}$ and 1,5 for greater than $100 \mathrm{~g} / \mathrm{d}$ ( 38 ). These data suggest that hepatitis $\mathrm{B}$ virus infection may modify the prognosis for alcoholic liver cirrhosis patients, especially in the developing of carcinogenesis.

Chronic HCV infection is another important risk factor for HCC.Some 180 million people worldwide (approximately $2 \%$ of world population) are currently estimated to be chronically infected with the virus $(3,12)$. The risk ofdeveloping $\mathrm{HCC}$ for apatient with $\mathrm{HCV}$-related cirrhosis is approximately $2-6 \%$ in year (39). In contrast with the trend observed in US and Western European countries, where the proportion of $\mathrm{HCV}$-related HCCs is increasing and will continue to increase due to the rise in $\mathrm{HCV}$ infection through continued transmission by drug abusers $(40,41)$, and in almost in the same way with some other countries $(42,43)$ we found that $8 \%$ of all HCCs were related to the $\mathrm{HCV}$ infection. Other risk factors are high viral load, increasing age, male gender and severe degree of hepatic fibrosis (44).

It is well known that the most important clinical risk factor for the development of $\mathrm{HCC}$ is cirrhosis. Our findings clearly showed that $89.3 \%$ of HCCs developed in cirrhotic liver. The high rate of co-existing cirrhosis in HCC patients have led to the assumption that pre-existing cirrhosis is an important prerequisite for hepatocarcinogenesis, although some HCCs do not arise in the observe of cirrhosis (45). All etiological form of cirrhosis may be complicated by the development of HCC, although not with equal likelihood. Apart from the etiology of the cirrhosis, the major factors predisposing to malignant transformation in cirrhotic patients are increasing age, duration of cirrhosis and male sex (6). The main causes of cirrhosis complicated by malignant transformation in this study were chronic HBV infection, concomitant HBV infection and alcoholism and alcoholism alone, and behind them, chronic HCV infection. Compatible with previous data (46), our study confirmed that HCC occurred at younger age in patients with concomitant HBV infection and alcoholism than those with HBV infection alone $(42.8 \pm 9.7$ vs $46.7 \pm 8.9)$ or alcoholism alone $(42.8 \pm 9.7$ vs $47.2 \pm 10.1)$ and that the rate of ChildPugh class A with patients with concomitant HBV infection and alcoholism was significantly less that individuals with HBV infection alone (56\% vs $73 \%$ ) or alcoholism alone (56\% vs $69 \%$ ). These data suggest that hepatitis B virus infection may modify the prognosis for alcoholic liver cirrhosis patients, especially in the development of carcinogenesis.So that, alcoholic cirrhotic patients with concomitant HBV infection should be carefully screened for HCC consequently of more severe liver pathology.

One of the limitation that should be underlined is the lack of determination of aflatoxin exposure, particularly of patients with cryptogenic cirrhosis, through the presence of the 


\section{International Journal of Science and Research (IJSR) \\ ISSN (Online): 2319-7064}

Index Copernicus Value (2013): 6.14 | Impact Factor (2014): 5.611

aflatoxin metabolites in urine or aflatoxin-albumin adduct in serum.

In conclusions, the incidence of $\mathrm{HCC}$ has doubled in Albania between 2000 and 2014 and is likely to continue to increase for the near future consequently to the high prevalence of $\mathrm{HBV}$ infection (HBsAg more than $8 \%$ in general population) and expected to increase in the future of $\mathrm{HCV}$ infection. Apart from the HBV infection, heavy alcohol consumption as well responsible for the observed increase of HCC and that alcohol cirrhotic patients with concomitant HBV infection significantly influenced for the increased incidence of HCC. HBV vaccination of agespecific cohorts (young adolescents) and high risk population for acquiring $\mathrm{HBV}$ infection should be the high priority in reducing the incidence of $\mathrm{HCC}$.

\section{Conflict of Interest}

None declared.

\section{References}

[1] Jemal A, Bray F, Center MM et al. Global cancer statistics. Cancer J Clin 2011; 61: 69-90.

[2] Mittals S, El-Serag HB. Epidemiology of hepatocellular carcinoma : consider the population. J ClinGastroenterol 2013; 47 Suppl: S2-6.

[3] Bosch FX,Ribes J, Diaz M, Clerier R. Primary liver cancer: worldwide incidence and trends. Gastroenterology 2004; 127:153-156.

[4] Parking DM, Bray F, Ferlay J, Pisani P. Global cancer statistics 2002. Cancer J Clin 2005;55:74-108.

[5] El-Serag HB, Davila JA, Peterson NJ, Mc Glynn KA. The continuing increase in the incidence of hepatocellular carcinoma in United States : An update. Ann Intern Med 2003;139:817-823.

[6] Fattovich G, Straffolini T, Zagni I, Donato F. Hepatocarcinoma in cirrhosis: incidence and risk factors. Gastroenterology2004;127:S35-50.

[7] Sherman M. Hepatocellular carcinoma :epidemiology,risk factors, and screening. SeminLiv Dis 2005;25:143-154.

[8] Altekruse SF, Mc Glynn KA, Reichman ME. Hepatocellular carcinoma incidence, mortality, and survival trends in the United States from 1975 to 2005. J ClinOncol 2009;27:1485-91.

[9] Venook PP, Papandeou C, Furuse J et al. The incidence and epidemiology of hepatocellular carcinoma : A global and regional perspective. The Oncologist 2010;15Suppl 4: 5-13.

[10] Michael CK. Prevention of hepatocellular carcinoma. Annals of Hepatology 2010;9;2:120-132.

[11] Maya GG. Viral hepatitis, non-alcoholic liver disease and alcohol as risk factors for hepatic carcinosis. Chin ClinOncol 2013;2(4):32.

[12] El-Serag HB. Epidemiology of viral hepatitis and hepatocellular carcinoma. Gastroenterology 2012;142:1264-73.e.1.

[13] Yang JD, Kim WR, Coelho R et al. Cirrhosis is present in most patients with hepatitis B and hepatocellular carcinoma. ClinGastroenterolHepatol 2011; 9: 64-70.
[14] Davila J, Morgan RO, ShaibY et al. Hepatitis C infection and the increase incidence of hepatocellular carcinoma : a population-based study. Gastroenterology 2004; 127:1372-80.

[15] Mancebo A, Gonzales-Diegues ML, Cadahia V et al. Annual incidence of hepatocellular carcinoma among patients with alcoholic cirrhosis and identification of risk groups. ClinGastroenterolHepatol 2013;11: 95101.

[16] Welzel TM, Granbard BI, Quraishi S et al. Populationattributable fraction of risk factors for hepatocellular carcinoma in the United States. Ann J Gastroenterol 2013;108:1314-21.

[17] Sudakin DL. Diataryaflatoxin exposure and chemoprevention of cancer : J TocicolClinToxicol 2003; 41: 195-204.

[18] Starley BQ, Calcagno CJ, Harrison SA. Non-alcoholic fatty liver disease and hepatocellular carcinoma : a weighty connection. Hepatology 2011; 51: 1820-32.

[19] Mandishona E, McPhail AP, Gordeuk VB et al. Dietary iron overload as a risk factor for hepatocellular carcinoma in Black Africans. Hepatology 1998;27:1563-6.

[20] Gaiani S, Gramantieri L, Venturoli N et al. What is the criterion for differentiation chronic hepatitis from compensated cirrhosis ? A prospective study comparing ultrasonography and percutaneous liver biopsy. J Hepatol 1997;27:979-98.

[21]Bruix J, Sherman M. Management of hepatocellular carcinoma. Hepatology 2005;42:1208-1236.

[22] Llovet DM, Burroughs A, Bruix J. Hepatocellular carcinoma. Lancet 2003;362:1907-191

[23] Fattovich G, Bortolotti F, Donato F. Natural history of chronic hepatitis B : special emphasis on disease progression and prognostic factors. $\mathbf{J}$ Hepatol 2008;48:335-352.

[24] Kane MA. Global status of hepatitis B immunization. Lancet 1996;348:696.

[25] Kane MA. Status of hepatitis B immunization programs in 1998. Vaccine 1998;16Suppl: S104-S108.

[26] Margolis HS, Alter MJ, Hadler SC. Hepatitis B : evolving epidemiology and implications for control. SeminLiv Dis 1991;11:84-92.

[27] Alter MJ. Epidemiology of hepatitis in Europe and worldwide. EASL International Consensus Conference on Hepatitis B, 2002; Sept, Geneva.

[28] Santantonio T, Lo Caputo S, Germinanio C et al. Prevalence of hepatitis virys infection in Albanian refuugies. Eur J Epidemiol 1993;9:537-540.

[29] Daleko GN, Zervou E, Karabini F, Tsiannos EV. Prevalence of viral markers among refugees from Southern Albania : increased incidence of infection with hepatitis A,B and D viruses. Eur J GastroenterolHepatol 1995;7:553-558.

[30] Resuli B, Prifti S, Kraja B et al. Epidemiology of hepatitis B virus infection in Albania. W J gastroenterol 2009;21, 15 ( 7 ): 849-852.

[31]Zanetti AR, Van Dame P, Shouval D. The global impact of vaccination against hepatitis $\mathrm{B}$ : a historical overview. Vaccine 2008; 26: 6266-73.

[32] Chang MH. Hepatitis B virus and cancer prevention. Recent Results Cancer Res 2011; 188: 75-84. 
[33] Yuun JM, Ross RK, Stanczyk FZ et al. A cohort study of serum testosterone and hepatocellular carcinoma in Shanghai, China. Int J Cancer 1995; 65: 491-493.

[34] Resuli B, Babameto A, Dumani N et al. Prospective evaluation of alcohol consumption as predictor for development of alcoholic liver disease. International Liver Con Hepatocellular carcinoma in Austria :aetiologic and clinical characteristics at presentation. Eur J GastroenterolHepatol 2000;12:941-8.

[35] Hasan MM, Hwang LY, Hatten CJ et al. Risk factor for hepatocellular carcinoma : synergism of alcohol with viral hepatitis and diabetes mellitus. Hepatology 2002;36:1206-13.

[36] Schoninger-Hekele M, Muller C, Kutilek M et al. Hepatocellular carcinoma in Austria ;aetiologic and clinical characteristics at presentation. Eur J GastroenterolHepatol 2000;12:941-8.

[37] Ikeda S, Saitoh S, Suzuki I et al. Disease progression and hepatocellular carcinogenesis in patients with chronic viral hepatitis : a prospective observation of 2215 patients. J Hepatol 1998;28:933-938.

[38] Jee SH, Ohur H, Sull JW et al. Cigarette smoking, alcohol drinking, hepatitis B and risk for hepatocellular carcinoma in Korea. O Natl Cancer Inst 2004;96:18511856.

[39] Sangiovanni A, Del Nino E, Fasani P et al. Increased survival of cirrhotic patients with hepatocellular carcinoma detected durind surveillance. Gastroenterology 2004; 126: 1005-14.

[40]Rein DB, Wittenborn JS, Weinbaum CM et al. Forecasting the morbidity and mortality associated with prevalence cases of pre-cirrhotic chronic hepatitis $\mathrm{C}$ in the United States. Dig Liv Dis 2011,43;66-72.

[41]El-Serag. Epidemiology of hepatocellular carcinoma. CliLiv Dis 2001, 5; 87-107.

[42] Gao JD, Shao YF, XU Y. Tight association of hepatocellular carcinoma with HBV infection in North China. HepatobiliaryPancreat Dis Int 2005;4;4:46-49.

[43] Kumar R, Saraswat MK, Sharma BC et al. Characteristics of hepatocellular carcinoma in India : a retrospective analysis of 191 casa. QJM 2008; 101: 47985.

[44] Koiysawa K, Umemura $\mathrm{T}$, Ichijo $\mathrm{T}$ et al.Hepatocellularcarcinoma : Recent trends in Japan. Gastroenterology 2004;127: S17-S26.

[45] Gao J, Xie L, Xang WS, et al. Risk factors of hepatocellular carcinoma - current status and perspective. Asia Pac J Can Prev 2012;13:743-52.

[46] Chih-Wen Lin, ChihChe Lin, Lein-Roy MO et al. Heavy alcohol consumption increases the incidence of hepatocellular carcinoma in hepatitis B virus - related cirrhosis. J Hepatology 2013;58(4):730-734. 